\title{
Perception and representation of Mandarin fricatives
}

\author{
Yu-an Lu \\ Stony Brook University \\ yualu@ic.sunysb.edu
}

Mandarin Chinese has three palatals $\left[\mathrm{t} \epsilon, \mathrm{t} \epsilon^{\mathrm{h}}, \epsilon\right]$ that are in complementary distribution with the velars $\left[\mathrm{k}, \mathrm{k}^{\mathrm{h}}, \mathrm{h}\right]$, and the dentals $\left[\mathrm{ts}, \mathrm{ts}^{\mathrm{h}}, \mathrm{s}\right]$. The palatals co-occur with the high-vowels $[\mathrm{i}, \mathrm{y}]$ and pre-nuclear glides [j, $\mathrm{u}]$ while other series do not (Duanmu 2007).

(1) Complementary distribution of Mandarin fricatives

\begin{tabular}{ll}
\hline $\mathrm{tc}_{\mathrm{t}} \mathrm{t}^{\mathrm{h}} \mathrm{C}$ & occur before high-front vowels /i, y/ or glides /j, $\mathrm{y} /$ \\
\hline $\mathrm{ts} \mathrm{ts}^{\mathrm{h}} \mathrm{s}$ & occur before non-high-front vowels \\
$\mathrm{k} \mathrm{k}^{\mathrm{h}} \mathrm{x}$ & \\
\hline
\end{tabular}

The traditional definition of contrast has relied on the distribution of two given sounds: if two (phonetically similar) sounds are in complementary distribution and hence are predictable from the environment, then they are allophones of the same phoneme; if two sounds occur in the same environment and hence are unpredictable, then they are contrastive (Banksira 2000; Bloch 1950; Bullock \& Gerfen 2005; Dixon 1970; Harris 1951; Hualde 2004; Moulton 1962; Vennemann 1971). Several hypotheses on the representations of the palatals are therefore proposed as to which series the palatals should be identified with. Chao (1934) argues that $\left[\mathrm{t} \varphi \mathrm{t} \varphi^{\mathrm{h}} \varphi\right]$ should be identified with [k k $\left.{ }^{\mathrm{h}} \mathrm{x}\right]$, while Hartman (1944) and Duanmu (2007) argue that [tc $\mathrm{t} \varphi^{\mathrm{h}} \varphi$ ] should be identified with [ts ts ${ }^{\mathrm{h}} \mathrm{s}$ ]. On the other hand, Cheng (1973) argues that [t $\left.\mathrm{tc}^{\mathrm{h}} \mathrm{c}\right]$ should be independent/underlying segments.

(2) Hypotheses on the representation of the palatals

\begin{tabular}{|c|c|}
\hline$\left[\mathrm{tc} \mathrm{tc}^{\mathrm{h}} \varphi\right]$ as $/ \mathrm{k} \mathrm{k}^{\mathrm{h}} \mathrm{x} /$ & Chao (1934) \\
\hline$\left[\operatorname{tct} \operatorname{tc}^{\mathrm{h}} \mathrm{c}\right]$ as $/ \mathrm{ts}^{\mathrm{tg}} \mathrm{h} \mathrm{s} /$ & Hartman (1944) and Duanmu (2007) \\
\hline$\left[\operatorname{tct} \epsilon^{\mathrm{h}} \varphi\right]$ as $/ \operatorname{tc} \operatorname{tc}^{\mathrm{h}} \varphi /$ & Cheng (1973) \\
\hline
\end{tabular}

However, no studies have been done on the psychological reality of these sounds. Do native speakers of Mandarin perceive the palatals as the same category as other series in complementary distribution, or do they perceive them differently? The current study tested the palatal series and the dental series to see if they are variants of the same phoneme or different phonemes.

Following up on research showing priming effects between variant pronunciations of a category, but not between sounds belonging to different categories (Ernestus \& Baayen 2007; Ranbom \& Connine 2007; Sumner \& Samuel 2005), we investigate the extent to which the dental fricative [s] primes a palatal fricative $[\epsilon]$, or vice versa, by employing semantic priming and lexical decision tasks. We expect facilitation of lexical decision to a semantically related target to a [s]-prime, or to a [c]-prime (eg. [sijan] 'breed' primes [tonwu] 'animal'). We should find no/less facilitation when $[\mathrm{s} / \mathrm{c}]$ are changed into a contrastive sound (e.g. [sijan] $\rightarrow$ [fijan]). If we find facilitation when $[\mathrm{s}]$ is changed into $[6]$ or vice versa, then the two fricatives should be variants of the same 
category (e.g. [sijay] $\rightarrow$ [cijay]). On the contrary, if we do not find facilitation, then [s] and [c] should belong to different categories.

A total of 60 native Taiwan Mandarin speakers participated in the experiment. Participants were randomly assigned to three experimental conditions (20 in each). A norming pretest was done to select semantically related word pairs. A list of $[\mathrm{s} / \mathrm{c}]$ onset words was put together for the norming pretest, and $72[\mathrm{~s} / \mathrm{c}]$ onset words were selected from the list as primes (36 [s] words and 36 [6] words). Half of the list was matched up with related targets, and the other half was matched up with unrelated targets. The average response of the participants for the related primetarget pairs was 39\%. The stimuli were recorded in a sound-dampened room by a male native Mandarin phonetician. Three versions of the wordlist corresponding to three experimental conditions were created. Version 1, corresponding to SAME condition, was created by crosssplicing a single token of $[\mathrm{s}]$ or $[\mathrm{c}]$ into the stimuli using the Praat software package (http://www.praat.org), so that all the stimuli had physically the same [s] or [c] token to avoid participants judging on the naturalness of the stimuli. Version 2, corresponding to SWAPPING condition, resembled version 1 except for swapping [s] and [6] in the stimuli (e.g., [sijay] $\rightarrow *$ [cijaj]; [cijan] 'banquet' $\rightarrow *$ [sijan]). Version 3, corresponding to CONTRASTIVE condition, resembled version 1 except for changing [s] and [c] in the stimuli into [f] (e.g., [sijan] $\rightarrow *[$ fijan]; [6ijan] $\rightarrow *[$ fijan]). 108 filler trials were added (18 with real word targets and 90 with pseudoword targets) to avoid the development of strategies in the responses. Filler primes all have non-fricative onsets.

(3) Stimuli

\begin{tabular}{lll}
\hline & 72 primes & \\
& $1 .[\mathrm{s}] \rightarrow[\mathrm{s}] ;[\mathrm{c}] \rightarrow[\mathrm{c}]$ & \\
\cline { 2 - 3 } Between-subject design & $2 .[\mathrm{s}] \rightarrow[\mathrm{c}] ;[\mathrm{c}] \rightarrow[\mathrm{s}]$ & \\
\cline { 2 - 3 } & $3 .[\mathrm{s}] \rightarrow[\mathrm{f}] ;[\mathrm{c}] \rightarrow[\mathrm{f}]$ & 36 unrelated targets \\
& Fillers & 18 real words \\
& & 90 pseudowords \\
\hline
\end{tabular}

(4) Three experimental conditions

\begin{tabular}{lll}
\hline \multicolumn{1}{c}{ SAME } & \multicolumn{1}{c}{ SWAPPING } & \multicolumn{1}{c}{ CONTRASTIVE } \\
\hline [si-jan] 'breed' $\rightarrow$ [ton-wu] 'animal' & $*[$ ci-jan $] \rightarrow[$ ton-wu $]$ & $*[$ fi-jay $] \rightarrow[$ ton-wu $]$ \\
[ci-jan] 'banquet' $\rightarrow$ [tcje-hun] 'wedding' & $*[$ si-jan $] \rightarrow[$ tcje-hun $]$ & $*[$ fi-jan $] \rightarrow[$ tcje-hun $]$ \\
\hline
\end{tabular}

Participants completed the experiment in groups or individually in a quiet room. All stimuli were presented binaurally over head-phones at a comfortable listening level. On each trial, participants were presented with an auditory prime, followed by a $500 \mathrm{~ms}$ ISI, followed by an auditory target. Participants were instructed to make a lexical decision for the second word of a pair. Example stimuli were provided and each participant completed a practice session with 8 trials. The experiment lasted approximately 12 minutes. 
As expected, the lexical decision reaction times were significantly faster for related targets than for unrelated targets. The mean RTs for the three experimental conditions are shown in (5) with standard deviations in parentheses.

(5) Reaction Time

\begin{tabular}{l|lll}
\hline \multicolumn{1}{r|}{ CONDITION } & \multicolumn{1}{|c}{ SAME } & \multicolumn{1}{c}{ SWAPPING } & \multicolumn{1}{c}{ CONTRASTIVE } \\
RELATION & $1014.94(110.34)$ & $1019.19(106.21)$ & $1062.26(135.16)$ \\
RELATED & $1137.34(116.27)$ & $1123.48(107.22)$ & $1133.46(139.57)$ \\
UNRELATED & 122.4 & 104.29 & 71.2 \\
\hline PRIMING EFFECT & &
\end{tabular}

Two-way ANOVAs (CONDITION: SAME, SWAPPING, CONTRASTIVE X RELATION: RELATED or UNRELATED) were performed for subject $(F 1)$ and item $(F 2)$. Overall, reaction times were significantly faster for related targets than for unrelated targets $(F 1(1,57)=171.660, p<.001$; $F 2(1,210)=47.836, p<.001)$, as we can see from the two columns in (6). Planned comparisons showed that targets preceded by related primes were identified more quickly than unrelated primes in all three conditions ( $\operatorname{SAME} F 1(1,19)=85.445, p<.001, F 2(1,70)=23.178, p<.001$; SWAPPING $F 1(1,19)=44.004, p<.001, F 2(1,70)=19.767, p<.001$; CONTRASTIVE $F 1(1,19)=53.678$, $p<.001, F 2(1,70)=7.699, p<.01)$. Simple effect of CONDITION in RELATED was not significant $(F 1(2,57)=.985, p=.380, F 2(2,105)=2.815, p=.064)$ nor does the simple effect of CONDITION in UNRELATED $(F 1(2,57)=.069, p=.933, F 2(2,105)=.137, p=.873)$.

(6) CONDITION X RELATION

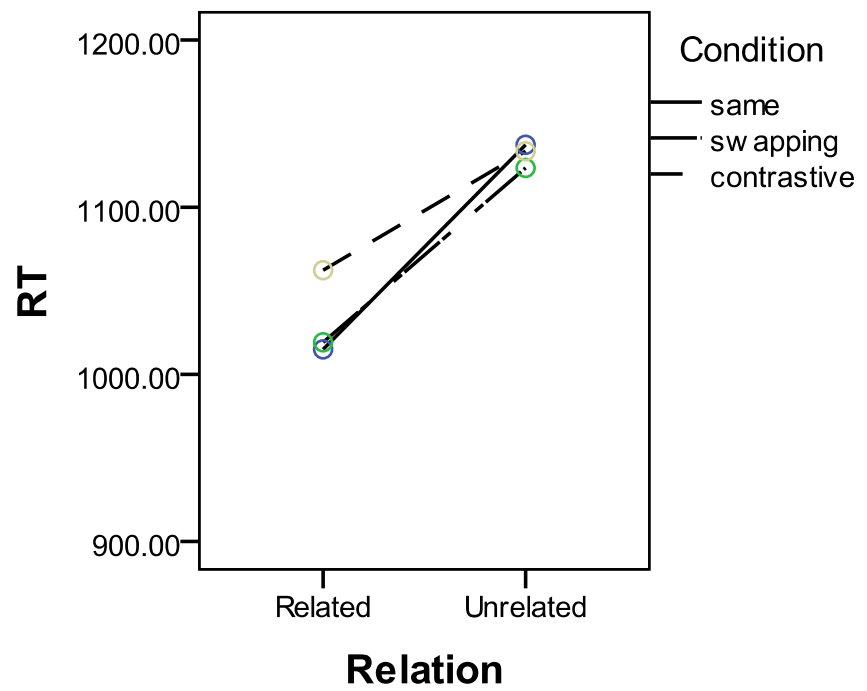

(7) Priming effect

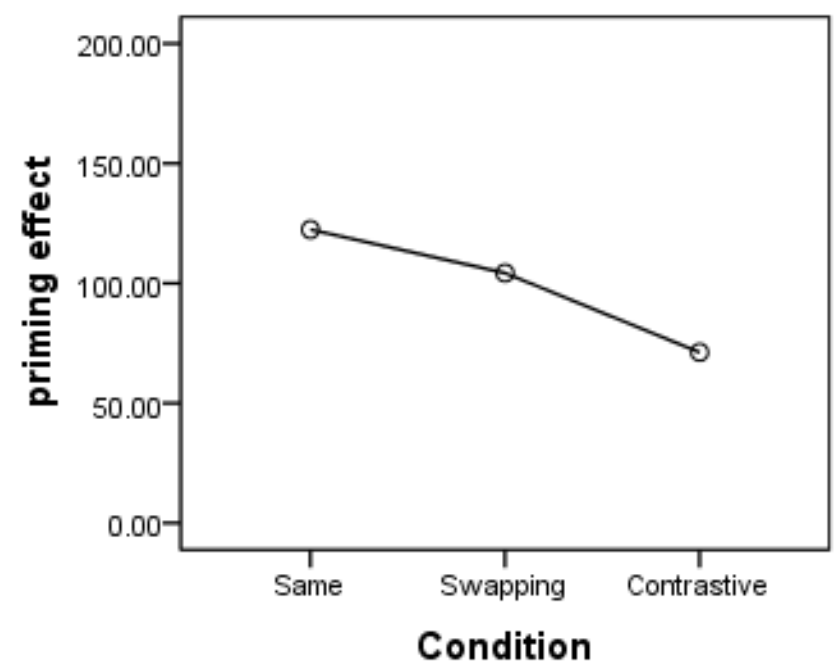

The factor CONDITION yielded a significant effect in an analysis on priming effects (difference of the RTs in RELATED and UNRELATED in each condition) $(F(2,117)=4.356, p<.05)$. Pairwise comparisons showed that only the priming effects in the SAME \& CONTRASTIVE conditions were statistically different $(p<.05)$; the other two pairwise comparisons (SAME \& SWAPPING, SWAPPING $\&$ CONTRASTIVE) were not different (both $p>.1$ ). In other words, only the two end points in (7) yielded a significant difference. 
We have found a priming effect for all three conditions, even for the CONTRASTIVE condition, though there was a clear RT difference for SAME \& CONTRASTIVE. However, there is no threeway difference in RT corresponding to same, allophonic or contrastive sounds. There are two possible explanations. First, this seems to suggest that the idea of phoneme categories is gradient rather than categorical (Hall 2009), so that we do not see the same results for SAME \& SWAPPING conditions (providing evidence that $[\mathrm{s}]$ and $[\mathrm{c}]$ are allophonic), nor the same results for SWAPPING \& CONTRASTIVE (providing evidence that $[\mathrm{s}]$ and $[6]$ are phonemic). Second, the gradient results could be associated with phonetic similarity. Connine et al. (1993) showed that nonwords that differed in one or two linguistic features resulted in priming effects (e.g., *battern primes pattern). Note that in this experiment, the primes in both SWAPPING and CONTRASTIVE conditions are nonwords. The results we see could be reflecting the phonetic similarities among $[\mathrm{s}],[\mathrm{c}]$, and [f]. One direction for future research is to add another condition in which $[\mathrm{s} / \mathrm{c}]$ are changed into a non-fricative sound, say [t]. If there is still priming effects but the effects are less than CONTRASTIVE condition, we can conclude that the results we have are associated with the idea that phoneme categories are gradient rather than categorical. Another direction is to replicate the experiment with real words, so that we can examine if the results are associated with phonetic similarities.

\section{References}

Banksira, Deqif Petros. (2000). Sound Mutations: The Morphophonology of Chaha: John Benjamins Publishing Co.

Bloch, Bernard. (1950). Studies in colloquial Japanese IV phonemics. Language 26.86-125.

Bullock, Barbara E. \& Chip Gerfen. (2005). The preservation of schwa in the converging phonological system of Frenchville (PA) French. Bilingualism: Language and Cognition 8.117-30.

Chao, Yuen-Ren. (1934). The non-uniqueness of phonemic solutions of phonetic systems. Bulletin of the Institute of History and Philology, Academia Sinica IV.363-97.

Cheng, Chin-Chuan. (1973). A Synchronic Phonology of Mandarin Chinese: De Gruyter Mouton.

Connine, Cynthia M., Dawn G. Blasko \& Debra Titione. (1993). Do the beginnings of spoken words have a special status in auditory word recognition? Journal of Memory and Language 32.193-210.

Dixon, Robert Malcolm Ward. (1970). Proto-Australian laminals. Oceanic Linguistics 9.79-103.

Duanmu, San. (2007). The Phonology of Standard Chinese: Oxford University Press.

Ernestus, Mirjam \& Harald Baayen. (2007). Paradigmatic effects in auditory word recognition: The case of alternating voice in Dutch. Language and Cognitive Processes 22.1-24.

Hall, Kathleen Currie. (2009). A Probabilistic Model of Phonological Relationships from Contrast to Allophony: The Ohio State University.

Harris, Zellig S. (1951). Methods in Structural Linguistics. Chicago: University of Chicago Press.

Hartman, Lawton M. (1944). The segmental phonemes of the Peiping dialect. Language 20.28-42.

Hualde, José Ignacio. (2004). Quasi-phonemic contrasts in Spanish. WCCFL 23: Proceedings of the 23rd West Coast Conference on Formal Linguistics, ed. by Chand, Vineeta, Ann Kelleher, Angelo J. Rodriguez \& Banjamin Schmeiser, 374-98. Somerville, MA: Cascadilla Press.

Moulton, William G. (1962). The Sounds of English and German, A Systematic Analysis of the Contrasts Between the Sound Systmes. Chicago: University of Chicago Press.

Ranbom, Larissa J. \& Cynthia M. Connine. (2007). Lexical representation of phonological variation in spoken word recognition. Journal of Memory and Language 57.273-98.

Sumner, Meghan \& Arthur G. Samuel. (2005). Perception and representation of regular variation: The case of final /t/. Journal of Memory and Language 52.322-38.

Vennemann, Theo. (1971). The phonology of Gothic vowels. Language 47.90-132. 